\title{
The prognostic significance of tumour cell detection in the peripheral blood versus the bone marrow in 733 early-stage breast cancer patients
}

Timothy J Molloy ${ }^{1}$, Astrid J Bosma ${ }^{1}$, Lars O Baumbusch ${ }^{2,3}$, Marit Synnestvedt ${ }^{4}$, Elin Borgen ${ }^{5}$, Hege Giercksky Russnes ${ }^{5}$, Ellen Schlichting ${ }^{4}$, Laura J van't Veer ${ }^{1}$ and Bjørn Naume ${ }^{4,6^{*}}$

\begin{abstract}
Introduction: The detection of circulating tumour cells (CTCS) in the peripheral blood and disseminated tumour cells (DTCs) in the bone marrow are promising prognostic tools for risk stratification in early breast cancer. There is, however, a need for further validation of these techniques in larger patient cohorts with adequate follow-up periods.

Methods: We assayed CTCS and DTCs at primary surgery in 733 stage I or II breast cancer patients with a median follow-up time of 7.6 years. CTCs were detected in samples of peripheral blood mononuclear cells previously stored in liquid-nitrogen using a previously-developed multi-marker quantitative PCR (QPCR)-based assay. DTCs were detected in bone marrow samples by immunocytochemical analysis using anti-cytokeratin antibodies.

Results: CTCs were detected in $7.9 \%$ of patients, while DTCs were found in $11.7 \%$. Both CTC and DTC positivity predicted poor metastasis-free survival (MFS) and breast cancer-specific survival (BCSS); MFS hazard ratio (HR) $=2.4$ $(P<0.001) / 1.9(P=0.006)$, and BCSS HR $=2.5(P<0.001) / 2.3(P=0.01)$, for $C T C / D T C$ status, respectively). Multivariate analyses demonstrated that CTC status was an independent prognostic variable for both MFS and BCSS. CTC status also identified a subset of patients with significantly poorer outcome among low-risk node negative patients that did not receive adjuvant systemic therapy (MFS HR $2.3(P=0.039)$, BCSS HR $2.9(P=0.017)$ ). Using both tests provided increased prognostic information and indicated different relevance within biologically dissimilar breast cancer subtypes.
\end{abstract}

Conclusions: These results support the use of CTC analysis in early breast cancer to generate clinically useful prognostic information.

\section{Introduction}

In recent years breast cancer survival rates have been steadily increasing, partly due to earlier diagnoses as a result of increased awareness and widespread mammography screening programmes. Despite these advances, approximately one-third of patients will develop distant metastasis, which represents the terminal step in the progression of the disease. The relative paucity of

\footnotetext{
* Correspondence: Bjorn.Naume@oslo-universitetssykehus.no ${ }^{4}$ Division of Surgery and Cancer Medicine, Oslo University Hospital Radiumhospitalet, Postboks 4953, Nydalen, 0424 Oslo, Norway Full list of author information is available at the end of the article
}

accurate prognostic tests has made it difficult to identify these high-risk patients to allow for more optimized adjuvant treatment decisions. Similarly, many patients at low risk of developing disseminated disease undergo toxic adjuvant chemotherapy treatments that are of little benefit. There is consequently a need for new prognostic tests with significantly increased sensitivity and specificity, particularly for those patients at the early stages of their disease.

Tumour cells in the bone marrow (disseminated tumour cells (DTCs)) or circulating in the peripheral blood (circulating tumour cells (CTCs)), are potential 
progenitors of distant metastasis and may, therefore, represent important targets of such tests [1-12]. Indeed, the detection of CTCs and DTCs has been associated with both disease progression in metastatic breast cancer [13-15], as well as disease recurrence and distant spread in early-stage breast cancer $[1,3,5,6,16]$. Bone marrow has traditionally been the primary compartment in which the prognostic value of the detection of these cells has been investigated, as it is a common homing organ for tumour cells of epithelial origin [17]. While the detection of DTC is of prognostic significance $[1,3,5]$, it has the inherent disadvantage of needing an invasive procedure for sample collection and, additionally, is less suitable for serial sampling for monitoring adjuvant treatment response. The use of peripheral blood as an alternative sampling material has, therefore, gained significant interest in recent years as it does not suffer from these drawbacks. However, there remains a need for good quality studies to confirm the clinical relevance of CTCs in larger patient cohorts, particularly in comparison to DTCs. So far relatively few such studies in early breast cancer have included mature outcome data. Furthermore, only limited data exist on the comparison of CTCs and DTCs in this context, and studies have shown variable results $[7,18,19]$. Whether CTC detection could replace DTC detection is still an open question, and the value of CTCs versus DTCs may differ among patients as a consequence of different tumour biology and/or dissemination characteristics.

In the current study, we used our previously-developed [2,20] multi-marker QPCR-based CTC assay on thawed samples of liquid nitrogen-stored peripheral blood mononuclear cells (PBMC) from 733 early-stage breast cancer patients collected at the time of diagnosis. In addition, this patient series previously had bone marrow samples assayed for DTCs [1], which afforded an opportunity to directly compare the prognostic relevance of CTC and DTC detection in the same large patient group.

\section{Materials and methods}

\section{Patient and sample selection}

Between May 1995 and December 1998, samples of peripheral blood and bone marrow were collected from 920 stage I-II primary breast cancer patients immediately prior to primary surgery, at five hospitals in Norway (Ullevål University Hospital (now Oslo University Hospital Ullevål), Norwegian Radium Hospital (now Oslo University Hospital Norwegian Radium Hospital), Bærum Hospital, Aker University Hospital, and Buskerud Hospital), as described previously [1]. After excluding patients from whom peripheral blood mononuclear cells (PBMC) were either unavailable for this study $(n=149)$ or who were eligible for and/or received preoperative systemic therapy (pT3/4 patients; $n=38$ ), which would likely distort the true CTC levels, PBMC were thawed from liquid nitrogen storage for CTC analysis. Bone marrow samples from the same patients $(n=$ 733) had previously been analysed for the presence of DTCs [1]. Patients were treated with breast-conserving surgery or breast ablation and axillary clearance in addition to adjuvant therapy where required, as described in Table 1. Systemic adjuvant treatment was given according to the national guidelines between 1995 and 1998. Patients with node negative disease having either tumours $\leq 2 \mathrm{~cm}$ or grade 1 tumours 2 to $5 \mathrm{~cm}$ in diameter did not receive systemic adjuvant treatment. In addition, patients $>65$ years of age did not receive chemotherapy. The standard adjuvant chemotherapy regimen consisted of six cycles (3 qw) of intravenous cyclophosphamide $600 \mathrm{mg} / \mathrm{m}^{2}$, methotrexate $40 \mathrm{mg} / \mathrm{m}^{2}$, and fluorouracil $600 \mathrm{mg} / \mathrm{m}^{2}$. Ten patients received highdose chemotherapy. Tamoxifen was used as endocrine therapy in hormone receptor-positive patients. Radiotherapy was offered after breast-conserving surgery for all patients and after mastectomy for node-positive premenopausal patients and postmenopausal patients with four or more positive lymph nodes. The follow-up consisted of clinical examination at 6- to 12-month intervals at the hospital outpatient departments or by the patients' primary doctors, with mammography annually. Further diagnostic work-up was performed only if the patients had symptoms or signs of progression. The median follow-up time for metastasis-free survival was 7.1 years, and for breast cancer-specific survival 8.3 years. Written informed consent was obtained from all participants and the study was approved by the Regional Ethic Committee.

\section{Control subjects}

For the CTC study, 16 patients with metastatic breast cancer $\left(\mathrm{M}_{1}\right.$ disease, according to the Union Internationale Contre le Cancer criteria) were included as clinical "positive controls" as based on our previous studies [2] the majority (>90\%) were expected to have circulating tumour cells. They were invited to participate if they were between treatments or soon to start subsequent palliative treatment modality. A total of 28 samples of peripheral blood from healthy controls into which different numbers (5 to 1,000) of cultured breast tumour cells derived from a mixture of six breast cancer cell lines (MCF7, CAMA1, T47D, SKBR3, ZR-75-1, and MDA-MB-231) were also tested in parallel as a second positive control group. Twenty-five healthy (negative) control subjects matched for gender and age and randomly selected from hospital and scientific staff were also freshly collected. Mononuclear cells from these control groups were separated and stored frozen for up 
Table 1 Clinical characteristics of the stage I to II breast cancer patients included in the study

\begin{tabular}{|c|c|c|c|c|c|c|c|c|}
\hline & & \multicolumn{2}{|c|}{ All patients } & \multicolumn{2}{|c|}{ CTC positive } & \multicolumn{2}{|c|}{ CTC negative } & \multirow[b]{2}{*}{$P$-value* } \\
\hline & & Number & Percent & Number & Percent & Number & Percent & \\
\hline Number: & & 733 & $100 \%$ & 58 & $7.9 \%$ & 675 & $92.1 \%$ & \\
\hline \multirow[t]{4}{*}{ Age: } & $<35$ & 15 & $2.0 \%$ & 1 & $1.7 \%$ & 14 & $2.1 \%$ & 0.503 \\
\hline & 35 to 45 & 89 & $12.1 \%$ & 10 & $17.2 \%$ & 79 & $11.7 \%$ & \\
\hline & 45 to 55 & 203 & $27.7 \%$ & 18 & $31.0 \%$ & 185 & $27.4 \%$ & \\
\hline & $>55$ & 426 & $58.1 \%$ & 29 & $50.0 \%$ & 397 & $58.8 \%$ & \\
\hline \multirow[t]{4}{*}{ Tumour size: } & $\mathrm{pT1}(<2.0 \mathrm{~cm})$ & 405 & $55.3 \%$ & 30 & $51.7 \%$ & 375 & $55.6 \%$ & $0.373^{\S}$ \\
\hline & pT2 $(2.0$ to $5.0 \mathrm{~cm})$ & 225 & $30.7 \%$ & 20 & $34.5 \%$ & 205 & $30.4 \%$ & \\
\hline & pT3 (> $5.0 \mathrm{~cm})$ & 2 & $0.3 \%$ & 2 & $3.4 \%$ & 0 & $0 \%$ & \\
\hline & pTX & 60 & $8.2 \%$ & 3 & $5.2 \%$ & 57 & $8.4 \%$ & \\
\hline \multirow[t]{4}{*}{ Histological grade: } & Grade 1 & 187 & $25.5 \%$ & 9 & $15.5 \%$ & 178 & $26.4 \%$ & 0.186 \\
\hline & Grade 2 & 350 & $47.7 \%$ & 29 & $50.0 \%$ & 321 & $47.6 \%$ & \\
\hline & Grade 3 & 186 & $25.4 \%$ & 18 & $31.0 \%$ & 168 & $24.9 \%$ & \\
\hline & Unknown & 10 & $1.4 \%$ & 2 & $3.4 \%$ & 8 & $1.2 \%$ & \\
\hline \multirow[t]{3}{*}{ ER status: } & Positive & 516 & $70.4 \%$ & 31 & $53.4 \%$ & 485 & $71.9 \%$ & 0.002 \\
\hline & Negative & 179 & $24.4 \%$ & 24 & $41.4 \%$ & 155 & $23.0 \%$ & \\
\hline & Unknown & 38 & $5.2 \%$ & 3 & $5.2 \%$ & 35 & $5.2 \%$ & \\
\hline \multirow[t]{3}{*}{ PR status: } & Positive & 401 & $54.7 \%$ & 25 & $43.1 \%$ & 376 & $55.7 \%$ & 0.046 \\
\hline & Negative & 288 & $39.3 \%$ & 30 & $51.7 \%$ & 258 & $38.2 \%$ & \\
\hline & Unknown & 44 & $6.0 \%$ & 3 & $5.2 \%$ & 41 & $6.1 \%$ & \\
\hline \multirow[t]{3}{*}{ HER2 status: } & Positive & 83 & $11.3 \%$ & 15 & $25.9 \%$ & 68 & $10.1 \%$ & $<0.001$ \\
\hline & Negative & 610 & $83.2 \%$ & 40 & $69.0 \%$ & 570 & $84.4 \%$ & \\
\hline & Unknown & 40 & $5.5 \%$ & 3 & $5.2 \%$ & 37 & $5.5 \%$ & \\
\hline \multirow[t]{5}{*}{ Node status: } & $\mathrm{pNO}$ & 483 & $65.9 \%$ & 34 & $58.6 \%$ & 449 & $66.5 \%$ & 0.089 \\
\hline & $\mathrm{pN} 1$ & 150 & $20.5 \%$ & 11 & $19.0 \%$ & 139 & $20.6 \%$ & \\
\hline & $\mathrm{pN} 2$ & 53 & $7.2 \%$ & 9 & $15.5 \%$ & 44 & $6.5 \%$ & \\
\hline & $\mathrm{pN} 3$ & 22 & $3.0 \%$ & 3 & $5.2 \%$ & 19 & $2.8 \%$ & \\
\hline & $\mathrm{pNX}$ & 25 & $3.4 \%$ & 1 & $1.7 \%$ & 24 & $3.6 \%$ & \\
\hline \multirow[t]{3}{*}{ Vascular invasion: } & Yes & 116 & $15.8 \%$ & 12 & $20.7 \%$ & 104 & $15.4 \%$ & 0.171 \\
\hline & No & 524 & $71.5 \%$ & 35 & $60.3 \%$ & 489 & $72.4 \%$ & \\
\hline & Unknown & 93 & $12.7 \%$ & 11 & $19.0 \%$ & 82 & $12.1 \%$ & \\
\hline \multirow[t]{3}{*}{ Bone marrow status: } & Positive & 86 & $11.7 \%$ & 17 & $29.3 \%$ & 69 & $10.2 \%$ & $<0.001$ \\
\hline & Negative & 605 & $82.5 \%$ & 35 & $60.3 \%$ & 570 & $84.4 \%$ & \\
\hline & Unknown & 42 & $5.7 \%$ & 6 & $10.3 \%$ & 36 & $5.3 \%$ & \\
\hline \multirow[t]{4}{*}{ Adjuvant systemic treatment: } & No treatment & 391 & $53.3 \%$ & 28 & $48.3 \%$ & 363 & $53.8 \%$ & 0.392 \\
\hline & Chemo +/- Hormonal & 155 & $21.1 \%$ & 16 & $27.6 \%$ & 139 & $20.6 \%$ & \\
\hline & Hormonal therapy Only & 164 & $22.4 \%$ & 11 & $19.0 \%$ & 153 & $22.7 \%$ & \\
\hline & Unknown & 23 & $3.1 \%$ & 3 & $5.2 \%$ & 20 & $3.0 \%$ & \\
\hline \multirow[t]{3}{*}{ Metastasis: } & Number & 149 & $20.3 \%$ & 22 & $37.9 \%$ & 127 & $18.8 \%$ & 0.001 \\
\hline & Median time to event & \multicolumn{2}{|c|}{36.4 months } & \multicolumn{2}{|c|}{30.8 months } & \multicolumn{2}{|c|}{37.2 months } & \\
\hline & Median followup time & \multicolumn{2}{|c|}{84.3 months } & \multicolumn{2}{|c|}{78.6 months } & \multicolumn{2}{|c|}{85.2 months } & \\
\hline \multirow[t]{3}{*}{ Breast cancer-specific deaths: } & Number & 122 & $16.6 \%$ & 19 & $32.8 \%$ & 103 & $15.3 \%$ & $<0.001$ \\
\hline & Median time to event & $42.9 r$ & onths & 54.3 & onths & $42.0 r$ & onths & \\
\hline & Median followup time & 99.2 & onths & $94.1 \mathrm{r}$ & onths & 99.2 & onths & \\
\hline
\end{tabular}

${ }^{*} P$-value (Pearson Chi-squared test).

$\S=$ Chi-squared analysis included pT1 and pT2 tumours only.

CTC, circulating tumour cell; ER, estrogen receptor; HER2, human epidermal growth factor receptor 2; PR, progesterone receptor 
to one week to mimic the processing and storage conditions of the patient samples, before being thawed and assayed. For the DTC study, bone marrows from 98 healthy controls were assayed.

\section{Sampling and processing of peripheral blood (PB)}

A total of $50 \mathrm{~mL}$ of blood was collected immediately prior to primary surgery. Mononuclear cells, including any tumour cells present, were separated from the whole blood samples using Ficoll Hypaque (BD, Breda, Netherlands) and stored frozen in aliquots of $20 \times 10^{6}$ cells (except from 30 patients, from which less than $20 \times 10^{6}$ cells were available) in liquid nitrogen until tumour cell enrichment (10 to 15 years later). Tumour cells were separated from a single aliquot of peripheral blood mononuclear cells (PBMCs) using anti-EpCAM (clone HEA-125) and anti-ErbB2 Micro Beads $\left(\right.$ MACS $^{\circledR}$; Miltenyi Biotec, Leiden, Netherlands) according to the manufacturer's instructions. In brief, beads were incubated with the PBMCs for 30 minutes at $4{ }^{\circ} \mathrm{C}$, after which labelled cells were collected on a magnetic separation column. After removal of the column from the magnetic field, the retained $\mathrm{EpCAM}^{+}$and/or ErbB2 ${ }^{+}$cells were eluted, and stored at $-70^{\circ} \mathrm{C}$ in lysis buffer (5 M Guanidine thiocyanate (Merck, Darmstadt, Germany), pH 6.8, $0.05 \mathrm{M}$ tris, $0.02 \mathrm{M}$ EDTA, 1.3\% Triton) until mRNA isolation and cDNA synthesis.

\section{mRNA isolation and CDNA synthesis}

Total RNA was precipitated from the cell lysate and dissolved in lysis buffer from the $\mu \mathrm{MACS}^{\mathrm{TM}}$ One-step cDNA kit (Miltenyi Biotec). Oligo(dT) Micro Beads were added and the mixture placed onto the $\mu \mathrm{MACS}$ column in the thermo MACSTM Separator (Miltenyi Biotec, Leiden, Netherlands). The isolated mRNA was directly converted into cDNA as per the manufacturer's instructions, with an additional elution with $20 \mu \mathrm{l}$ of elution buffer, resulting in a total volume of $70 \mu \mathrm{l}$.

\section{Quantitative real-time PCR}

Quantitative real-time PCR primers (Sigma Genosys, Cambridge, UK) and 5'-fluorescently FAM-labelled probes (Applied Biosystems, Nieuwerkerk a/d IJssel, The Netherlands) were designed using the Perkin Elmer Primer Express ${ }^{\circledR}$ software (PE, Foster City, CA, USA) based on the published sequences of CK19, p1B, EGP-2, PS2, mammaglobin and SBEM as previously described [20] (Table 2). All primers were designed to be intron-spanning to preclude amplification of genomic DNA. Commercially available primers and probes for the "housekeeping" genes $\beta$-actin and glyceraldehyde-3phosphate dehydrogenase (GAPDH) (Applied Biosystems) were also used.

Serially diluted cDNA synthesized from the amplified RNA of a pool of 82 snap frozen breast cancer tissues was used to generate standard curves for control and marker gene expression. For all cDNA dilutions, fluorescence was detected from 0 to 50 PCR cycles for the control and marker genes in single-plex reactions, which allowed the deduction of the $\mathrm{C}_{\mathrm{T}}$-value (threshold cycle) for each product. The $\mathrm{C}_{\mathrm{T}}$-value is the PCR cycle at which a significant increase in fluorescence is detected due to the exponential accumulation of PCR products and is represented in arbitrary units (TaqMan Universal PCR Master Mix Protocol, Applied Biosystems) [21]. The "housekeeping" genes $\beta$-actin and GAPDH were used to confirm reaction efficiency. Each measurement was performed in triplicate. Quality control measures for the PCR reactions included the addition of a genomic DNA control and a non-template control.

\section{Quadratic discriminant analysis (QDA) 'CTC score' calculation}

QDA was used to calculate a 'CTC score' representing CTC presence or absence for each sample, as previously described [22,23], using the expression data of the four best marker genes (CK19, p1B, EGP and MmGl). QDA is a statistical approach to find the combination of

Table 2 Primer sequences for the six marker genes used for CTC detection

\begin{tabular}{|c|c|c|c|}
\hline Gene & Accession & Sequence & Probe (5'FAM-3'TAMRA) \\
\hline p1B & $\begin{array}{l}\text { [Genbank: } \\
\text { L15203] }\end{array}$ & $\begin{array}{l}\text { Sense: CTGAGGAGTACGTGGGCCTG Antisense: } \\
\text { AGTCCACCCTGTCCTTGGC }\end{array}$ & CTGCAAACCAGTGTGCCGTGCC \\
\hline PS2 & $\begin{array}{l}\text { [Genbank: } \\
\text { X00474] }\end{array}$ & $\begin{array}{l}\text { Sense: GAGGCCCAGACAGAGACGTG Antisense: } \\
\text { CCCTGCAGAAGTGTCTAAAATTCA }\end{array}$ & CTGCTGTITGACGACACCGTTCG \\
\hline CK19 & $\begin{array}{l}\text { [Genbank: } \\
\text { NM002276] }\end{array}$ & $\begin{array}{l}\text { Sense: CTACAGCCACTACTACACGAC Antisense: } \\
\text { CAGAGCCTGTTCCGTCTCAAA }\end{array}$ & CACCATTGAGAACTCCAGGATTGTCCTGC \\
\hline EGP2 & $\begin{array}{l}\text { [Genbank: } \\
\text { M32306] }\end{array}$ & $\begin{array}{l}\text { Sense: CAGTTGGTGCACAAAATACTGTCA Antisense: } \\
\text { CCATTCATITCTGCCTTCATCA }\end{array}$ & TTGCTCAAAGCTGGCTGCCAAATGTT \\
\hline SBEM & $\begin{array}{l}\text { [Genbank: } \\
\text { AF414087] }\end{array}$ & $\begin{array}{l}\text { Sense: CTCTTGGGGAGTITCCATCTTCTG Antisense: } \\
\text { CTICATCATCAGCAGGACCAGTAG }\end{array}$ & CCCAGAATCCGACAACAGCTGCTCC \\
\hline $\mathrm{MmGl}$ & $\begin{array}{l}\text { [Genbank: } \\
\text { AF015224] }\end{array}$ & $\begin{array}{l}\text { Sense: TTCTTAACCAAACGGATGAAACTCT Antisense: } \\
\text { GGTCTTGCAGAAAGTTAAAATAAATCAC }\end{array}$ & TGCTGTCATATATTAATTGCATAAACACCTCAACATTG \\
\hline
\end{tabular}


quadratic and linear functions of variables (in this case marker genes), which leads to the optimal separation between groups (in this case metastatic breast cancer patients and healthy volunteers). It is a generalization of Fisher's Linear Discrimination Analysis (LDA), which allows only linear functions [24]. A positive discriminant score indicates the presence of tumour cells in a sample, and conversely a negative discriminant score indicates their absence. QPCR measurement and QDA data analysis in this way offer a simple and objective estimate of tumour cell presence in a given sample.

\section{Sampling and processing of bone marrow (BM)}

The processing and analysis of DTC has been previously described [1]. Briefly, BM was collected from patients under general anaesthesia just before primary surgery for suspected breast cancer. A total of $40 \mathrm{~mL}$ of BM was aspirated from anterior and posterior iliac crests bilaterally (10 mL per site) and after separation by density centrifugation, mononuclear cells $(\mathrm{MNC})$ were collected and cytospins were prepared $\left(5 \times 10^{5} \mathrm{MNC} /\right.$ slide). Four slides were incubated with the anticytokeratin monoclonal antibodies (mAbs) AE1 and AE3 (Sanbio, Uden, The Netherlands), and the same number of slides were incubated with an isotype-specific irrelevant control mAb. The visualization step included the alkaline phosphatase/anti-alkaline phosphatase reaction, and the slides were counterstained with hematoxylin to visualize nuclear morphology. The cytospins were manually screened by light microscopy by a single pathologist (EB). The determination of the presence of DTC was based on Consensus morphology criteria [25]. In the DTC-positive patients, a median of 1 cell was detected, with a mean of 98 cells (range 1 to 7,500). Of the bone marrow samples from 98 healthy controls, 4 contained $\geq 1$ cell ( 3 with 1 cell, 1 with 2 cells) which were scored positive by the described technique. Those patients with a DTC positive event in the negative control (isotype specific), were excluded from DTC interpretation in the specific test (AE1AE3), which improved the specificity of the DTC analysis.

\section{Statistical analysis}

The primary endpoints for the survival analysis was breast cancer-specific survival (BCSS), which was measured from the date of surgery to breast cancer-related death or otherwise censored at the time of the last follow-up visit or at non cancer-related death, and metastasis-free survival (MFS), measured in the same way. Kaplan-Meier survival curves for time to distant recurrences and breast cancer-specific death were plotted. $P$ values were computed by the log-rank test. Cox proportional hazards regression was used for univariate and multivariate (stepwise backward elimination) analysis of prognostic impact of relevant variables. For statistical analysis, the SPSS (Version 15.0.1; SPSS, Inc, Chicago, IL, USA) software was used.

\section{Results}

\section{Detection of CTC}

Results from a total of 733 stage I to II breast cancer patients with biomaterial available at the time of surgery for both CTC and DTC analysis are presented. For CTC detection, samples of peripheral blood from a group of healthy individuals (negative controls) and metastatic breast cancer patients (positive controls) were processed the same way as the patient samples. These were used to calculate weights for each of the tumour marker genes used in the CTC assay and to set the threshold of CTC positivity. In an analogous fashion, 28 blood samples from healthy volunteers into which cultured breast tumour cells were spiked were also investigated as positive controls, since all should contain detectable levels of tumour marker gene expression. This sample set generated comparable tumour marker weights to the metastatic patients. This analysis also demonstrated that the assay gave a positive CTC score when as few as one tumour cell per $\mathrm{mL}$ was present in the sample (data not shown).

Using the above data to tune the QDA CTC score calculation, 58 of the $733(7.9 \%)$ patients had a positive CTC score and determined CTC-positive, versus 0 out of 25 healthy controls in the negative control group. The CTC result was compared to clinical and histopathological parameters, as well as the DTC status, as described in Table 1. Patients determined to be CTCpositive were significantly more likely to have ER-negative $(P=0.002$ (Pearson Chi-square test)), PR-negative $(P=0.046)$, HER2-positive $(P<0.001)$ tumours, and have tumour cells present in the bone marrow $(P<$ 0.001).

\section{Circulating tumour cell status and patient outcome}

The median observation period for the patients following blood collection was 7.1 years for metastasis-free survival, and 8.3 years for breast cancer-specific survival. During these periods, 149 patients (20.3\%) experienced metastasis - $22(37.9 \%)$ of the CTC-positive patients, versus $127(18.8 \%)$ of the CTC-negative patients $(P=$ 0.001 (Pearson Chi-square test); Table 1). Cox regression analysis demonstrated that CTC status was a significant predictor of metastasis-free survival (MFS; hazard ratio $(\mathrm{HR})=2.4, P<0.001 ; 95 \%$ confidence interval $(\mathrm{CI})$ $=1.5$ to 3.9 ; Figure $1 \mathrm{~A}$; Table 3). Similarly, 122 patients (16.6\%) died from their disease during the follow-up period: 19 (32.8\%) CTC-positive patients, versus 103 (15.3\%) CTC-negative patients. CTC status was, therefore, also a significant prognostic factor for breast- 

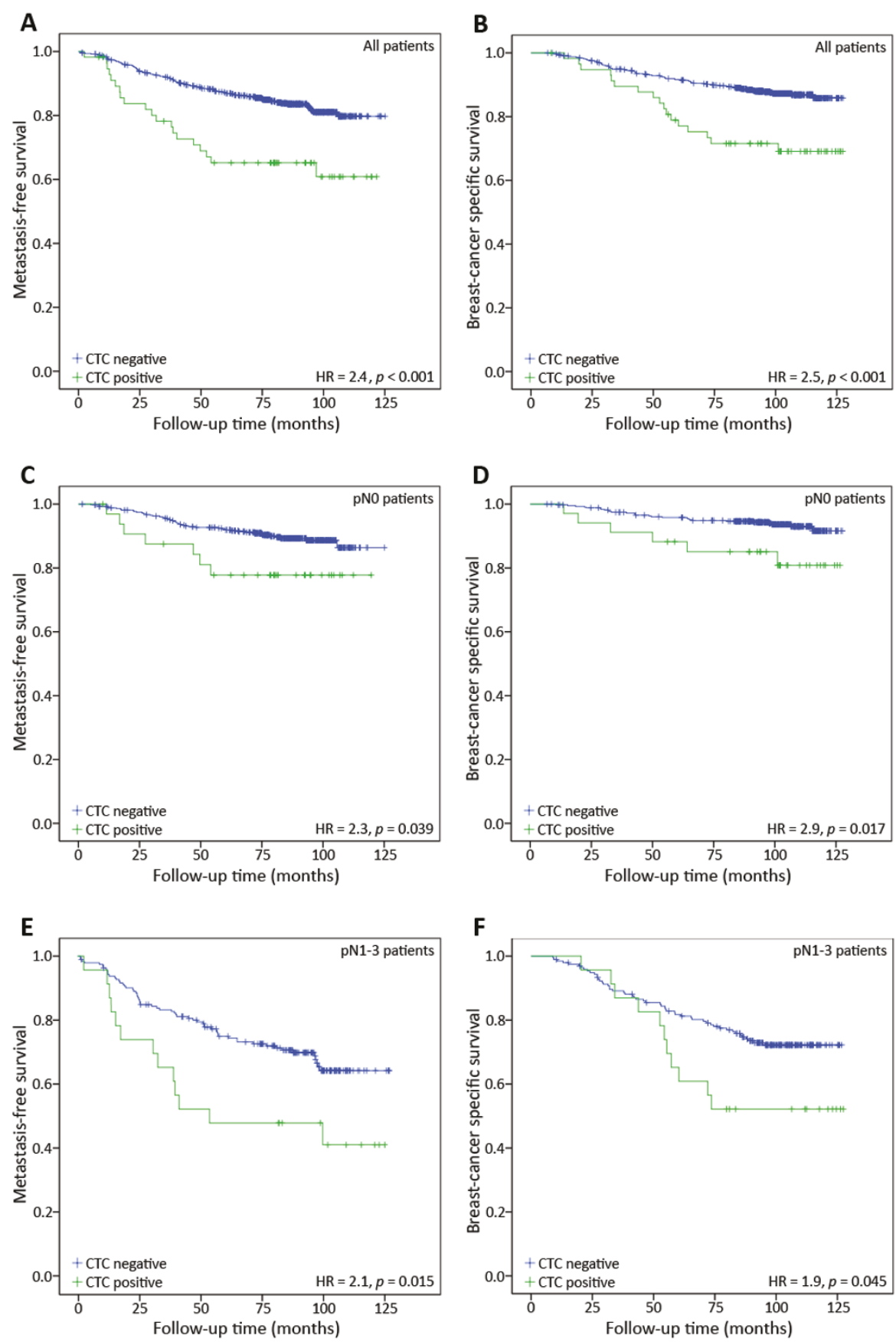

Figure 1 Metastasis-free survival (A, C, E) and breast-cancer specific survival (B, D, F) for all, (A, B), lymph-node negative, (C, D), and lymph-node positive $(E, F)$ patients.

cancer specific survival (BCSS; HR $=2.5, P<0.001 ; 95 \%$ $\mathrm{CI}=1.5$ to 4.3 ); Figure $1 \mathrm{~B}$; Table 3 ).

CTC status was next tested in a multivariate Cox regression model, including DTC status and standard prognostic clinical variables (lymph node status, histological grade, tumour size, hormone receptor status, HER2 status, and vascular invasion). In the final model, CTC status remained a significant prognostic factor for both relapse-free survival and breast cancer-specific survival (Table 4).

Within this cohort, 367 lymph node-negative patients were considered at low risk of metastasis according to the prevailing guidelines at the time of study accrual and did not receive systemic adjuvant treatment. Of 
Table 3 Univariate Cox regression analysis of CTC and DTC status for metastasis-free and breast cancer-specific survival

\begin{tabular}{rccccccc}
\hline & \multicolumn{2}{c}{$\begin{array}{c}\text { Metastasis-free } \\
\text { survival }\end{array}$} & \multicolumn{3}{c}{$\begin{array}{c}\text { Breast cancer-specific } \\
\text { survival }\end{array}$} \\
Clinical variable & $\boldsymbol{H R}$ & $\boldsymbol{P}$-value & $\mathbf{9 5 \%} \mathbf{C l}$ & $\boldsymbol{H R}$ & $\boldsymbol{P}$-value & $\mathbf{9 5 \% ~} \mathbf{C l}$ \\
\hline CTC status & 2.4 & $<0.001$ & 1.5 to 3.9 & 2.5 & $<0.001$ & 1.5 to 4.3 \\
DTC status & 1.9 & 0.006 & 1.2 to 2.9 & 2.3 & 0.001 & 1.4 to 3.7 \\
\hline
\end{tabular}

$\mathrm{Cl}$, confidence interval; CTC, circulating tumour cell; DTC, disseminated tumour cell; $\mathrm{HR}$, hazard ratio

these patients, those that were CTC-positive had a significantly higher risk of metastasis and breast cancer death than those that were CTC-negative (MFS HR = 3.0, $P=0.014$; BCSS HR $=3.6, P=0.011$ ) (Figure 2). In the subgroup of patients receiving chemotherapy (with or without hormonal treatment; $n=155$ ), CTC status was also prognostic (MFS HR $=2.3, P=0.042$; BCSS $\mathrm{HR}=3.1, P=0.012)$. For patients treated with hormonal therapy only $(n=164)$, survival differences according to CTC status were not statistically significant (MFS $\mathrm{HR}=1.3, P=0.701$; $\mathrm{BCSS} \mathrm{HR}=1.7, P=0.376)$.

\section{Circulating tumour cell status versus disseminated tumour cell status}

Previously, we reported the clinical significance of DTC status in this patient cohort (over a shorter follow-up period) by immunocytochemical detection of cytokeratin-positive cells [1]. This allowed the direct comparison of the prognostic value of CTC detection to DTC detection. Of the 733 patients included in the study, the bone marrow samples of 86 patients (11.7\%) contained DTCs. In univariate analyses DTC status was also a significant predictor of outcome, with a HR of 1.9 for MFS ( $P=$ $0.006)$ and $2.3(P=0.001)$ for BCSS (Table 3$)$. However, in the multivariate analyses including CTCs, DTC status fell below the level of significance (Table 4). Patients in whom tumour cells were detected in both peripheral blood and bone marrow had a significantly poorer outcome than those with tumour cells detected in only one or neither compartment (MFS $=3.5, P=0.001$; $\mathrm{BCSS}=$ 3.0, $P=0.008$; Figure 3). In addition, those patients who were exclusively CTC-positive or exclusively DTC-positive also had reduced survival as compared to patients who were negative for both $(\mathrm{CTC}+/ \mathrm{DTC}-\mathrm{BCSS} \mathrm{HR}=$ 2.2, $P=0.015 ; \mathrm{MFS}=1.9, P=0.034$. CTC-/DTC+ BCSS $\mathrm{HR}=2.1, P=0.003 ; \mathrm{MFS}=1.5, P=0.127$ ).

A subgroup univariate analysis revealed that DTC status was only prognostic in lymph node-positive patients $($ MFS HR $=2.1, P=0.004$ and BCSS HR $=2.1, P=$ 0.007), and not in lymph node-negative patients (MFS $\mathrm{HR}=0.6, P=0.378$ and BCSS HR $=1.0, P=0.978)$. CTC status however, appeared to be prognostic in both groups (MFS HR $=2.1, P=0.015$; BCSS HR $=1.9, P=$ 0.045 for lymph-node positive patients, and MFS HR = 2.3, $P=0.039$; BCSS HR $=2.9, P=0.017$ for lymphnode negative patients; Figure 1). When patients were subgrouped by ER, PR, and HER2 status, CTC status, but not DTC status, was significantly associated with survival for ER-negative and/or HER2-negative patients. For ER-positive patients, those with the presence of DTCs experienced reduced BCSS. This was not observed for CTC positive patients. Both CTC and DTC status were associated with MFS (Table 5). Of the 143 ER/PR/HER-negative ("triple negative") patients, CTC status, but not DTC status, was prognostic for both

Table 4 Multivariate Cox regression analysis of CTC and DTC status for metastasis-free and breast cancer-specific survival

\begin{tabular}{|c|c|c|c|c|c|c|}
\hline \multirow[b]{2}{*}{ Clinical variable } & \multicolumn{3}{|c|}{ Relapse-free survival } & \multicolumn{3}{|c|}{ Breast cancer-specific survival } \\
\hline & $H R$ & P-value & $95 \% \mathrm{Cl}$ & $H R$ & $P$-value & $95 \% \mathrm{Cl}$ \\
\hline CTC status $(\dagger)$ & 1.8 & 0.043 & 1.0 to 3.3 & 1.9 & 0.032 & 1.1 to 3.6 \\
\hline DTC status $(\dagger)$ & * & * & * & $*$ & * & * \\
\hline Lymph nodes (vs pNO) & & $<0.001$ & & & $<0.001$ & \\
\hline - pN1 & 2.2 & 0.001 & 1.4 to 3.5 & 2.6 & 0.001 & 1.5 to 4.5 \\
\hline$-\mathrm{pN} 2 / 3$ & 3.2 & $<0.001$ & 1.8 to 5.5 & 3.8 & $<0.001$ & 2.1 to 7.0 \\
\hline Histological grade (vs I) & & 0.053 & & & 0.049 & \\
\hline - grade $\|$ & 2.0 & 0.094 & 0.9 to 4.5 & 1.6 & 0.324 & 0.6 to 4.3 \\
\hline - grade III & 2.8 & 0.019 & 1.2 to 6.8 & 2.8 & 0.044 & 1.0 to 7.7 \\
\hline Tumour size $(<20 \mathrm{~mm}$ vs $>20 \mathrm{~mm})$ & 1.9 & 0.002 & 1.3 to 2.9 & 2.4 & $<0.001$ & 1.5 to 3.8 \\
\hline ER/PR status ( $\ddagger)$ & 1.7 & 0.028 & 1.1 to 2.7 & 1.9 & 0.018 & 1.1 to 3.1 \\
\hline HER2 status $(\dagger)$ & * & $*$ & $*$ & 1.8 & 0.024 & 1.1 to 3.1 \\
\hline Vascular Invasion (†) & 1.6 & 0.048 & 1.0 to 2.5 & 1.8 & 0.015 & 1.1 to 3.0 \\
\hline
\end{tabular}

*, not significant in final multivariate model; $\dagger$, positive versus negative; $\neq$, both negative versus either or both positive $\mathrm{Cl}$, confidence interval; CTC, circulating tumour cell; DTC, disseminated tumour cell; ER, estrogen receptor; HER2, human epidermal growth factor receptor 2; HR, hazard ratio; PR, progesterone receptor 

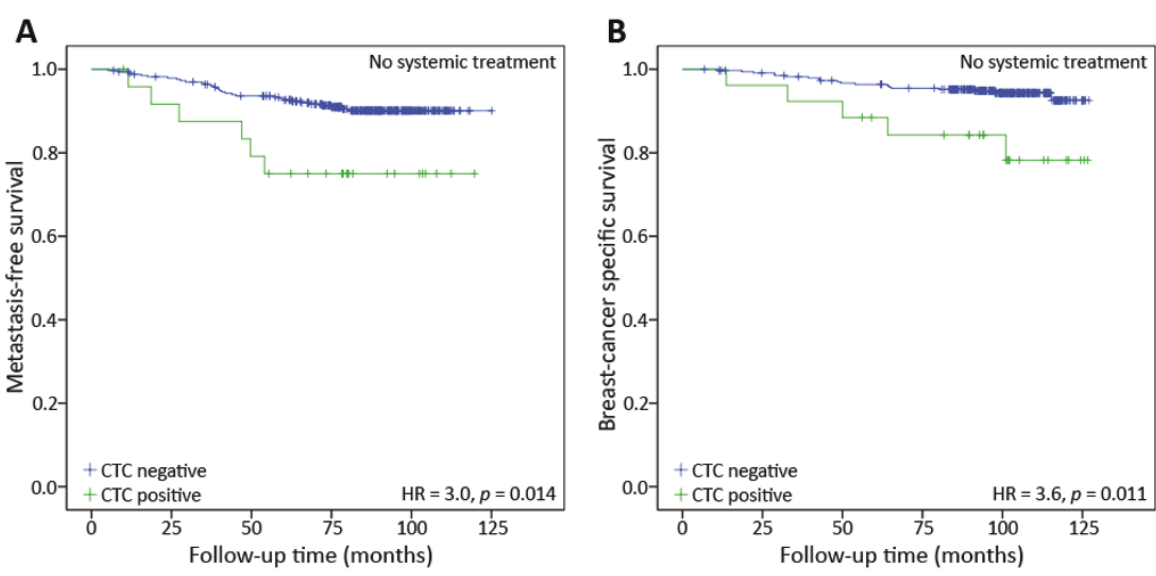

Figure 2 Kaplan-Meier plot of metastasis-free survival (A) and breast cancer specific survival (B) in patients who did not receive systemic adjuvant treatment $(\boldsymbol{n}=\mathbf{3 6 7})$. The CTC-positive patients had a poorer MFS and BCSS than CTC-negative patients (MFS HR $=3.0,95 \%$ $\mathrm{Cl}=1.2$ to $7.1, P=0.014 ; \mathrm{BCSS} \mathrm{HR}=3.6,95 \% \mathrm{Cl}=1.3$ to $9.6, P=0.011)$.

MFS $(\mathrm{HR}=2.1, P=0.034$ vs $\mathrm{HR}=1.1, P=0.869$, respectively) and $\mathrm{BCSS}(\mathrm{HR}=2.4, P=0.019$ vs $\mathrm{HR}=$ $1.1, P=0.846)$.

\section{Discussion}

We aimed to validate a previously-developed [2,20], highly sensitive multi-marker QPCR-based CTC assay in a large early-stage breast cancer patient cohort with mature outcome data. Bone marrow samples from these patients had previously been assayed for DTCs by immunocytochemical analysis using anti-cytokeratin antibodies [1]. This made it possible to also directly compare the prognostic value of the detection of tumour cells in the peripheral blood versus the bone marrow in the same large patient group.
In this cohort of 733 early-stage breast cancer patients, CTC status was a significant predictor of both metastasis-free and breast cancer-specific survival, in agreement with other studies $[2,6,7,26,27]$. To our knowledge, this is the largest published study on CTCs with mature outcome data. There was no significant difference in the distribution of many common clinical variables between CTC-positive and CTC-negative patients, barring that CTC-positive patients had tumours which were ER-negative, PR-negative and HER2-positive significantly more often, in agreement with other studies [28]. CTC-positive patients were in addition more likely to have tumour cells present in both their bone marrow, in accordance with the findings of Daskalaki et al., Pierga et al., and Müller et al. [7,29,30] (Table 1).
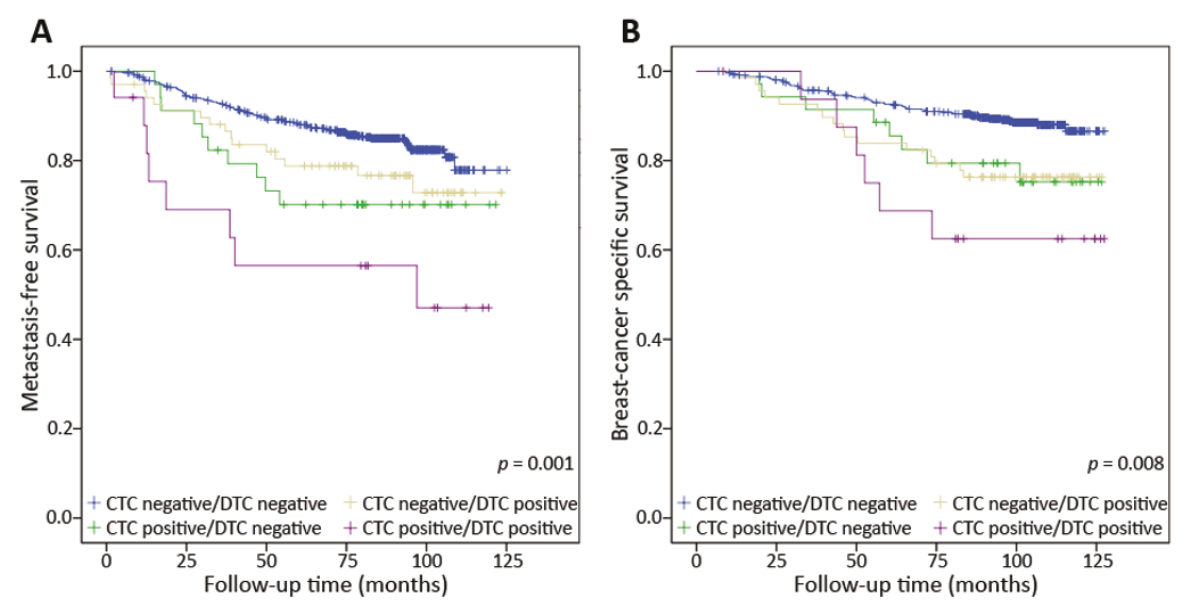

Figure 3 Kaplan-Meier plots demonstrating the effect of combining circulating and disseminated tumour cell status on metastasisfree survival (A) and breast-cancer specific survival (B). Those patients in whom tumour cells were detected in both the peripheral blood and bone marrow compartments have a significantly poorer survival compared to other groups (MFS $=3.5, P=0.001 ; \mathrm{BCSS}=3.0, P=0.008$ ). 
Table 5 Prognostic value of CTC and DTC detection in patients subgrouped by ER, PR, and HER2 status (Bold: P > 0.05)

\begin{tabular}{|c|c|c|c|c|c|c|c|c|}
\hline & & & \multicolumn{2}{|c|}{ ER } & \multicolumn{2}{|c|}{ PR } & \multicolumn{2}{|c|}{ HER2 } \\
\hline & & & Positive & Negative & Positive & Negative & Positive & Negative \\
\hline \multirow[t]{6}{*}{ Metastasis-free survival } & & $\mathrm{HR}$ & 2.2 & 2.2 & 2.6 & 2.3 & 1.2 & 2.9 \\
\hline & CTC status & $95 \% \mathrm{Cl}$ & 1.0 to 4.6 & 1.2 to 4.3 & 1.2 to 5.9 & 1.3 to 4.2 & 0.5 to 2.9 & 1.6 to 5.1 \\
\hline & & $P$-value & 0.037 & 0.015 & 0.018 & 0.006 & 0.691 & $<0.001$ \\
\hline & & $\mathrm{HR}$ & 2.1 & 1.1 & 1.6 & 1.5 & 1.2 & 1.6 \\
\hline & DTC status & $95 \% \mathrm{Cl}$ & 1.2 to 3.9 & 0.5 to 2.4 & 0.7 to 3.6 & 0.8 to 2.9 & 0.5 to 3.0 & 0.9 to 2.9 \\
\hline & & $P$-value & 0.015 & 0.902 & 0.243 & 0.179 & 0.712 & 0.103 \\
\hline \multirow[t]{6}{*}{ Breast cancer specific survival } & & HR & 1.9 & 2.4 & 2.0 & 2.8 & 1.4 & 2.9 \\
\hline & CTC status & $95 \% \mathrm{Cl}$ & 0.7 to 4.8 & 1.2 to 4.6 & 0.7 to 5.6 & 1.5 to 5.2 & 0.5 to 3.4 & 1.5 to 5.5 \\
\hline & & $P$-value & 0.180 & 0.01 & 0.200 & 0.001 & 0.504 & 0.001 \\
\hline & & $\mathrm{HR}$ & 2.9 & 1.1 & 1.4 & 2.0 & 1.6 & 1.7 \\
\hline & DTC status & $95 \% \mathrm{Cl}$ & 1.4 to 5.7 & 0.5 to 2.5 & 0.5 to 3.9 & 1.1 to 3.8 & 0.7 to 4.0 & 0.9 to 3.3 \\
\hline & & $P$-value & 0.003 & 0.832 & 0.560 & 0.025 & 0.268 & 0.098 \\
\hline
\end{tabular}

$\mathrm{Cl}$, confidence interval; CTC, circulating tumour cell; DTC, disseminated tumour cell; ER, estrogen receptor; HER2, human epidermal growth factor receptor 2; HR, hazard ratio; PR, progesterone receptor

Importantly, multivariate analysis demonstrated that CTC status provided prognostic information independent of other common clinical variables (Table 4). Furthermore, the CTC analysis discriminated outcome among those patients deemed at sufficiently low-risk of distant metastasis by traditional risk assessment to not receive systemic treatment. Indeed, these "low-risk" lymph node-negative CTC-positive patients had a fiveyear BCSS of $75.0 \%$, versus $93.0 \%$ for the CTC-negative patients (Figure 2). The identification of such a poor prognosis subgroup within a group of traditionallydefined "low risk" patients indicates the potential value of CTC detection in routine clinical use in conjunction with other prognostic tests.

Our results show that immunomagnetic tumour cell enrichment followed by multi-marker QPCR analyses on samples of PBMCs stored frozen for up to 15 years provides valuable clinical data. As expected, some cellular and nucleic acid degradation was observed in these samples after their removal from long-term storage, with tumour marker gene expression lower, variance higher (24-fold) and lower frequency of CTC positive cases (7.9\%) than that observed with our recent study using fresh material from a similar patient group $(n=82)$ [2]. None of the 25 healthy controls assayed were determined to be CTC-positive, which suggested high specificity. On the other hand, it should be noted that the possibility of occasional tumour marker gene expression in non-malignant cells of breast cancer patients cannot entirely be excluded, which may decrease true specificity in a clinical setting.

Interestingly, while CTC status was correlated with DTC status in these patients, it also provided additional prognostic information and outperformed DTC status in the multivariable analysis (Figure 3, Tables 4 and 5). Keeping in mind the retrospective design of this study, the presented results indicate that the CTC status especially improves the ability to predict outcome in the ER negative subset. It is possible that CTCs and DTCs to some extent reflect distinct aspects of the disease and that their presence and relevance depend on the biology of the underlying breast cancer: bone marrow is a compartment in which tumour cells may remain dormant for many years [17], whereas peripheral blood represents a transitory route for tumours that may be more rapidly proliferating and/or actively migrating. This is consistent with the observation that CTC-positive patients are significantly more likely to have ER-/PR-/HER2+ (Table 1) or triple negative tumours $(P=0.003$ by Pearson Chisquare), which tend to be more aggressive and exhibit high proliferative capacity [31]. DTCs by comparison, might have higher propensity to remain dormant but viable for extended periods, and, therefore, be more predictive of metastasis or relapse at later time points. This is consistent with our previous study in which the DTC status of a subset of patients from the current cohort was correlated to molecular subtype [32]. It was found that prognostic DTC status was most strongly correlated with patients with the less aggressive Luminal A-type tumours.

In some previous studies CTC status was found to be considerably less prognostic than DTC status $[10,11]$, in contrast to the present results. We cannot exclude the possibility that differences in the prognostic value of DTC detection in different studies may be due to the cytokeratin antibody used [33]. However, the novel CTC detection platform we have employed does offer high sensitivity and specificity by incorporating multi-marker 
QPCR-based detection and immunomagnetic tumour cell enrichment [20], resulting in increased prognostic power. This strategy also presents one limitation, however; by using anti-EpCAM and anti-ErbB2 Micro Beads for immunoselection, tumour cells that do not express or express low levels of EpCam or HER2 may not be enriched. Indeed, CTCs are known to be biologically heterogeneous (for review see [34]), and able to undergo phenotypic changes during migration. For example, some CTCs may lose EpCam in order to intravasate and reach circulation during epithelial-to-mesenchymal transition (EMT) [35]. Also, the use of an antibody directed against HER2 would favour the selection of HER2 positive CTCs, which may contribute to the observed significant overrepresentation of CTC-positive patients who have HER2-positive tumours.

Although there are biological explanations for differences in the clinical impact of CTCs and DTCs, different methodological principles for the detection of CTCs and DTCs, including the possibility for different sensitivity, might also contribute to incongruent results. Therefore, parallel analysis of CTCs and DTCs with the same methodological principle should be encouraged in future trials.

Our CTC assay was originally developed using fresh PBMCs, and in our previous study demonstrated more than twice the CTC positivity rate in early-stage patients than was observed using the liquid nitrogen-stored material here [2]. The use of our method on fresh PBMCs would, therefore, be expected to further increase the sensitivity and clinical utility of the assay. Future robust prospective studies are warranted to demonstrate this.

\section{Conclusions}

Our results add further evidence for the potential clinical value of CTC and DTC detection in risk stratification in early breast cancer. According to our data, approximately one in five breast cancer patients are likely to be CTC and/or DTC positive at the time of diagnosis and, significantly, a proportion of these will be classed as 'low-risk' by traditional prognostic measures and may not receive any form of systemic treatment, yet would probably derive considerable benefit from it. Our results also suggest that while CTC status may be easier to determine and monitor than DTC status due to the accessibility of the sampling material, both CTC and DTC status provide valuable clinical data that may be indicative of different disease aspects. Together, these results provide evidence that CTC and DTC detection generate prognostic information that would be useful in a clinical setting.

\section{Abbreviations}

BCSS: breast cancer-specific survival; BM: bone marrow; CTC: circulating tumour cell; DTC: disseminated tumour cell; ER: estrogen receptor; HER2: human epidermal growth factor receptor 2; HR: hazard ratio; LDA: Linear Discrimination Analysis; MNC: mononuclear cells; MFS: metastasis-free survival; PBMC: peripheral blood mononuclear cells; PR: progesterone receptor; QDA: quadratic discriminant analysis; (Q)PCR: (quantitative) polymerase chain reaction

\section{Acknowledgements}

This work was supported by the Sixth Framework Program of the European Commission as part of the international DISMAL collaboration for research into disseminated epithelial malignancies (Project LSHC-CT-2005-018911).

\section{Author details}

'Division of Experimental Therapy, The Netherlands Cancer Institute, Plesmanlaan 121, Amsterdam, 1066 CX, The Netherlands. ${ }^{2}$ Department of Genetics, Institute for Cancer Research, Oslo University Hospital Radiumhospitalet, Postboks 4953, Nydalen, 0424 Oslo, Norway. ${ }^{3}$ Biomedical Research Group, Department of Informatics, University of Oslo, Postboks 4953, Nydalen, 0424 Oslo, Norway. ${ }^{4}$ Division of Surgery and Cancer Medicine, Oslo University Hospital Radiumhospitalet, Postboks 4953, Nydalen, 0424 Oslo, Norway. ${ }^{5}$ Department of Pathology, Oslo University Hospital Radiumhospitalet, Postboks 4953, Nydalen, 0424 Oslo, Norway. ${ }^{6}$ Institute of Clinical Medicine, University of Oslo, Postboks 4953, Nydalen, 0424 Oslo, Norway.

\section{Authors' contributions}

$T M$ and $A B$ carried out CTC assays, performed data analysis and drafted the manuscript. LB, MS, EB and ES carried out DTC assays and the associated analyses. LV and BN were responsible for study design, patient accrual, statistical analysis, and drafting the manuscript. All authors read and approved the final manuscript.

\section{Competing interests}

The authors declare that they have no competing interests.

Received: 9 February 2011 Revised: 4 May 2011

Accepted: 14 June 2011 Published: 14 June 2011

\section{References}

1. Wiedswang G, Borgen E, Karesen R, Kvalheim G, Nesland JM, Qvist H, Schlichting E, Sauer T, Janbu J, Harbitz T, Naume B: Detection of isolated tumor cells in bone marrow is an independent prognostic factor in breast cancer. J Clin Oncol 2003, 21:3469-3478.

2. Molloy TJ, Bosma AJ, Helgason HH, van't Veer LJ: Detection and prediction of tumour cell dissemination in breast cancer. American Association of Cancer Research Annual Meeting 2008 San Diego, CA; 2008, 3696A.

3. Braun S, Vogl FD, Naume B, Janni W, Osborne MP, Coombes RC, Schlimok G, Diel IJ, Gerber B, Gebauer G, Pierga JY, Marth C, Oruzio D, Wiedswang G, Solomayer EF, Kundt G, Strobl B, Fehm T, Wong GY, Bliss J, Vincent-Salomon A, Pantel K: A pooled analysis of bone marrow micrometastasis in breast cancer. N Engl J Med 2005, 353:793-802.

4. De Giorgi U, Valero V, Rohren E, Dawood S, Ueno NT, Miller MC, Doyle GV, Jackson S, Andreopoulou E, Handy BC, Reuben JM, Fritsche HA, Macapinlac HA, Hortobagyi GN, Cristofanilli M: Circulating tumor cells and [18F]fluorodeoxyglucose positron emission tomography/computed tomography for outcome prediction in metastatic breast cancer. J Clin Oncol 2009, 27:3303-3311.

5. Braun S, Pantel K, Muller P, Janni W, Hepp F, Kentenich CR, Gastroph S, Wischnik A, Dimpfl T, Kindermann G, Riethmüller G, Schlimok G: Cytokeratin-positive cells in the bone marrow and survival of patients with stage I, II, or III breast cancer. N Engl J Med 2000, 342:525-533.

6. Ignatiadis M, Kallergi G, Ntoulia M, Perraki M, Apostolaki S, Kafousi M, Chlouverakis G, Stathopoulos E, Lianidou E, Georgoulias V, Mavroudis D: Prognostic value of the molecular detection of circulating tumor cells using a multimarker reverse transcription-PCR assay for cytokeratin 19 , mammaglobin A, and HER2 in early breast cancer. Clin Cancer Res 2008, 14:2593-2600.

7. Daskalaki A, Agelaki S, Perraki M, Apostolaki S, Xenidis N, Stathopoulos E, Kontopodis E, Hatzidaki D, Mavroudis D, Georgoulias V: Detection of cytokeratin-19 mRNA-positive cells in the peripheral blood and bone marrow of patients with operable breast cancer. Br J Cancer 2009, 101:589-597. 
8. Naume B, Borgen E, Kvalheim G, Karesen R, Qvist H, Sauer T, Kumar T, Nesland JM: Detection of isolated tumor cells in bone marrow in earlystage breast carcinoma patients: comparison with preoperative clinical parameters and primary tumour characteristics. Clin Cancer Res 2001, 7:4122-4129.

9. Borgen E, Beiske K, Trachsel S, Nesland JM, Kvalheim G, Herstad TK, Schlichting E, Qvist H, Naume B: Immunocytochemical detection of isolated epithelial cells in bone marrow: non-specific staining and contribution by plasma cells directly reactive to alkaline phosphatase. $J$ Pathol 1998, 185:427-434

10. Benoy $H$, Elst $H$, Philips $M$, Wuyts $H$, Van Dam P, Scharpe S, Van Marck E, Vermeulen PB, Dirix LY: Real-time RT-PCR detection of disseminated tumour cells in bone marrow has superior prognostic significance in comparison with circulating tumour cells in patients with breast cancer. Br J Cancer 2006, 94:672-680.

11. Wiedswang G, Borgen E, Schirmer C, Karesen R, Kvalheim G, Nesland JM Naume B: Comparison of the clinical significance of occult tumor cells in blood and bone marrow in breast cancer. Int J Cancer 2006, 118:2013-2019.

12. Meng S, Tripathy D, Frenkel EP, Shete S, Naftalis EZ, Huth JF, Beitsch PD, Leitch M, Hoover S, Euhus D, Haley B, Morrison L, Fleming TP, Herlyn D, Terstappen LW, Fehm T, Tucker TF, Lane N, Wang J, Uhr JW: Circulating tumor cells in patients with breast cancer dormancy. Clin Cancer Res 2004, 10:8152-8162.

13. Cristofanilli M, Budd GT, Ellis MJ, Stopeck A, Matera J, Miller MC, Reuben JM, Doyle GV, Allard WJ, Terstappen LW, Hayes DF: Circulating tumor cells, disease progression, and survival in metastatic breast cancer. $N$ Engl J Med 2004, 351:781-791

14. Weigelt B, Bosma AJ, Hart AA, Rodenhuis S, van 't Veer LJ: Marker genes for circulating tumour cells predict survival in metastasized breast cancer patients. Br J Cancer 2003, 88:1091-1094.

15. Cristofanilli M, Hayes DF, Budd GT, Ellis MJ, Stopeck A, Reuben JM, Doyle GV, Matera J, Allard WJ, Miller MC, Fritsche HA, Hortobagyi GN, Terstappen LW: Circulating tumor cells: a novel prognostic factor for newly diagnosed metastatic breast cancer. J Clin Oncol 2005, 23:1420-1430.

16. Xenidis N, Perraki M, Kafousi M, Apostolaki S, Bolonaki I, Stathopoulou A, Kalbakis K, Androulakis N, Kouroussis C, Pallis T, Christophylakis C, Argyraki K, Lianidou ES, Stathopoulos S, Georgoulias V, Mavroudis D: Predictive and prognostic value of peripheral blood cytokeratin-19 mRNA-positive cells detected by real-time polymerase chain reaction in node-negative breast cancer patients. J Clin Oncol 2006, 24:3756-3762.

17. Meads MB, Hazlehurst LA, Dalton WS: The bone marrow microenvironment as a tumor sanctuary and contributor to drug resistance. Clin Cancer Res 2008, 14:2519-2526.

18. Bidard FC, Vincent-Salomon A, Sigal-Zafrani B, Dieras V, Mathiot C, Mignot $L$, Thiery JP, Sastre-Garau X, Pierga JY: Prognosis of women with stage IV breast cancer depends on detection of circulating tumor cells rather than disseminated tumor cells. Ann Oncol 2008, 19:496-500.

19. Lang JE, Mosalpuria K, Cristofanilli M, Krishnamurthy S, Reuben J, Singh B, Bedrosian I, Meric-Bernstam F, Lucci A: HER2 status predicts the presence of circulating tumor cells in patients with operable breast cancer. Breast Cancer Res Treat 2009, 113:501-507.

20. Molloy TJ, Bosma AJ, van't Veer LJ: Towards an optimized platform for the detection, enrichment, and semi-quantitation circulating tumor cells. Breast Cancer Res Treat 2008, 112:297-307.

21. Bieche I, Laurendeau I, Tozlu S, Olivi M, Vidaud D, Lidereau R, Vidaud M: Quantitation of MYC gene expression in sporadic breast tumors with a real-time reverse transcription-PCR assay. Cancer Res 1999, 59:2759-2765.

22. Bosma AJ, Weigelt B, Lambrechts AC, Verhagen OJ, Pruntel R, Hart AA, Rodenhuis $S$, van 't Veer $L$ : Detection of circulating breast tumor cells by differential expression of marker genes. Clin Cancer Res 2002, 8:1871-1877.

23. Hand DJ: Statistical methods in diagnosis. Stat Methods Med Res 1992, 1:49-67.

24. Weigelt B, Verduijn $P$, Bosma AJ, Rutgers EJ, Peterse HL, van't Veer $L$ : Detection of metastases in sentinel lymph nodes of breast cancer patients by multiple mRNA markers. Br J Cancer 2004, 90:1531-1537.

25. Borgen E, Naume B, Nesland JM, Kvalheim G, Beiske K, Fodstad O, Diel I, Solomayer EF, Theocharous P, Coombes RC, Smith BM, Wunder E, Marolleau JP, Garcia J, Pantel K: Standardization of the immunocytochemical detection of cancer cells in BM and blood: I. establishment of objective criteria for the evaluation of immunostained cells. Cytotherapy 1999, 1:377-388.

26. Stathopoulou A, Vlachonikolis I, Mavroudis D, Perraki M, Kouroussis C, Apostolaki S, Malamos N, Kakolyris S, Kotsakis A, Xenidis N, Reppa D, Georgoulias V: Molecular detection of cytokeratin-19-positive cells in the peripheral blood of patients with operable breast cancer: evaluation of their prognostic significance. J Clin Oncol 2002, 20:3404-3412.

27. Xenidis N, Ignatiadis M, Apostolaki S, Perraki M, Kalbakis K, Agelaki S, Stathopoulos EN, Chlouverakis G, Lianidou E, Kakolyris S, Georgoulias V, Mavroudis D: Cytokeratin-19 mRNA-positive circulating tumor cells after adjuvant chemotherapy in patients with early breast cancer. J Clin Oncol 2009, 27:2177-2184.

28. Fehm T, Hoffmann O, Aktas B, Becker S, Solomayer EF, Wallwiener D, Kimmig R, Kasimir-Bauer S: Detection and characterization of circulating tumor cells in blood of primary breast cancer patients by RT-PCR and comparison to status of bone marrow disseminated cells. Breast Cancer Res 2009, 11:R59.

29. Pierga JY, Bonneton C, Vincent-Salomon A, de Cremoux P, Nos C, Blin N Pouillart $\mathrm{P}$, Thiery JP, Magdelenat $\mathrm{H}$ : Clinical significance of immunocytochemical detection of tumor cells using digital microscopy in peripheral blood and bone marrow of breast cancer patients. Clin Cancer Res 2004, 10:1392-1400.

30. Muller V, Stahmann N, Riethdorf S, Rau T, Zabel T, Goetz A, Janicke F, Pantel $\mathrm{K}$ : Circulating tumor cells in breast cancer: correlation to bone marrow micrometastases, heterogeneous response to systemic therapy and low proliferative activity. Clin Cancer Res 2005, 11:3678-3685.

31. Carey LA, Perou CM, Livasy CA, Dressler LG, Cowan D, Conway K, Karaca G, Troester MA, Tse CK, Edmiston S, Deming SL, Geradts J, Cheang MC, Nielsen TO, Moorman PG, Earp HS, Millikan RC: Race, breast cancer subtypes, and survival in the Carolina Breast Cancer Study. JAMA 2006, 295:2492-2502

32. Naume B, Zhao X, Synnestvedt M, Borgen E, Russnes HG, Lingjaerde OC, Stromberg M, Wiedswang G, Kvalheim G, Karesen R, Nesland JM, BørresenDale AL, Sørlie T: Presence of bone marrow micrometastasis is associated with different recurrence risk within molecular subtypes of breast cancer. Mol Oncol 2007, 1:160-171.

33. Effenberger KE, Borgen E, Eulenburg CZ, Bartkowiak K, Grosser A, Synnestvedt M, Kaaresen R, Brandt B, Nesland JM, Pantel K, Naume B: Detection and clinical relevance of early disseminated breast cancer cells depend on their cytokeratin expression pattern. Breast Cancer Res Treat 2010, 125:729-38

34. Mavroudis D: Circulating cancer cells. Ann Oncol 2010, 21(Suppl 7) vii95-vii100.

35. Bonnomet A, Brysse A, Tachsidis A, Waltham M, Thompson EW, Polette M, Gilles C: Epithelial-to-mesenchymal transitions and circulating tumor cells. J Mammary Gland Biol Neoplasia 2010, 15:261-273.

doi:10.1186/bcr2898

Cite this article as: Molloy et al:: The prognostic significance of tumour cell detection in the peripheral blood versus the bone marrow in 733 early-stage breast cancer patients. Breast Cancer Research 2011 13:R61.

\section{Submit your next manuscript to BioMed Central and take full advantage of:}

- Convenient online submission

- Thorough peer review

- No space constraints or color figure charges

- Immediate publication on acceptance

- Inclusion in PubMed, CAS, Scopus and Google Scholar

- Research which is freely available for redistribution 